\title{
UMA LEITURA DA EDUCAÇÃO AMBIENTAL NAS PRÁTICAS ALFABETIZADORAS
}

\author{
Tamíris de Lima Pereira ${ }^{1}$
}

\author{
Guilherme Silveira²
}

Celso Sanchez $z^{3}$

\section{Renata Monteiro ${ }^{4}$}

RESUMO: Este trabalho demonstra os primeiros resultados do projeto de pesquisa "Que bicho é esse?" que se desenvolve na Universidade Federal do Estado do Rio de Janeiro (UNIRIO). Esta pesquisa se articula com o Fórum de Alfabetização, Leitura e Escrita (FALE) desenvolvido mensalmente na mesma universidade, e que, busca possibilitar um espaço aberto de reflexão e trocas entre a academia e as professoras alfabetizadoras. Neste contexto, nosso objetivo é analisar o discurso e as práticas alfabetizadoras das professoras participantes. Os primeiros resultados nos permitem identificar um campo de conflitos simbólicos e a complexidade do tema que abrange interfaces sociais, científicas, tecnológicas e ambientais. Neste sentido, adotamos como referencial teórico a abordagem do Ensino de Ciências sob a perspectiva Ciência, Tecnologia, Sociedade e Ambiente (CTSA).

Palavras-Chaves: Ensino de Ciências; Práticas Alfabetizadoras; Educação Ambiental, CTSA.

\section{INTRODUÇÃO}

\footnotetext{
${ }_{1}^{1}$ Graduando Pedagogia - UNIRIO - tamirislima.pereira@gmail.com

2 Graduando Pedagogia - UNIRIO - guisilveira88@hotmail.com

3 Docente do departamento de didática da Escola de Educação - UNIRIO celsosanchez@hotmail.com

${ }^{4}$ Mestranda do Programa de Pós-Graduação em Educação da UNIRIO/bolsista CAPES renatas monteiro@hotmail.com
} 
O projeto de pesquisa "Que bicho é esse?" é coordenado pelo Prof. Dr. Celso Sánchez na Universidade Federal do Estado do Rio de Janeiro - UNIRIO se desenvolve em articulação com o Fórum de Alfabetização, Leitura e Escrita (FALE) que ocorre na mesma universidade, mensalmente, sendo coordenado pela Prof ${ }^{-}$Dr $^{\text {a }}$. Carmen Sanches. Este fórum se caracteriza por ser um espaço aberto onde professores do ensino fundamental e seus alunos trocam experiências com o objetivo de estabelecer uma relação dialógica com os membros da comunidade acadêmica. Desta forma, buscamos analisar as interações realizadas no fórum em torno da temática do Ensino de Ciências e Educação Ambiental nas práticas alfabetizadoras, tendo em vista as relações e os conflitos estabelecidos entre Ciência, Tecnologia, Sociedade e Ambiente (CTSA).

A metodologia se baseia na análise do discurso das narrativas das professoras alfabetizadoras, uma vez que, entendemos que suas falas podem nos dar pistas para compreensão dos significados que abarcam os saberes e fazeres de suas práticas. Neste sentido, reconhecemos Certeau (1994) quando coloca a bricolagem como algo que demanda uma ação onde a técnica de pesquisa não deve ser padronizada, mas se adaptar as circunstâncias do contexto e aos recursos disponíveis. Tomando como base essa definição, analisaremos as "bricolagens" desenvolvidas pelas professoras alfabetizadoras, tendo como pressuposto, que este conceito é de suma importância para percebermos as táticas e estratégias que são/foram desenvolvidas, nas palavras do autor, "uma teoria do relato é indissociável de uma teoria das práticas" (CERTEAU, 2002, p. 153).

Apesar das transformações tecno-científicas exercerem influência no ensino, a educação escolar ainda é concebida, em grande parte, à luz das práticas tradicionais, enraizadas na transmissão do conhecimento na forma que Freire concebe como educação bancária de perspectiva anti-dialógica, pautada na centralidade do professor. Os professores atuam, muitas vezes, de modo a inibir o que Freire (2003) chama de "curiosidade epistemológica", que 
proporciona ao indivíduo a compreensão do objeto de estudo motivado pela curiosidade e interesse. Pensamos que para mudar essa "antiga" prática seja necessário que o educador compreenda o sentido da educação e do processo de ensino/aprendizagem sob novos paradigmas (SANCHEZ, 2008).

Salientamos ainda a importância do campo ético-moral na formação do sujeito, sendo a escola um dos ambientes sociais co-participantes do desenvolvimento destes princípios. Neste sentido, a Educação Ambiental como prática escolar deve se inserir muito além das aulas de ecologia, possibilitando elementos que conduzam a questionamentos e reflexões quanto aos valores éticos-morais individuais e da coletividade, dando ao aluno condições de reconhecer os conflitos sócio-ambientais e tomar de decisões conscientes relacionadas as dimensões sociais, políticas e éticas.

Fumagalli (1993) (apud MALAFAIA e RODRIGUES, 2008) defende que toda criança possui o direito de aprender ciências. Logo, a Educação Ambiental vinculada a esse contexto deve se comprometer em auxiliar os alunos na compreensão do mundo no qual estão inseridos. Segundo Freire (2003) o processo educativo deve contribuir ao entendimento do mundo a partir da realidade do aluno, de modo que, o educador não seja o principal agente deste processo, aquele que guarda as verdades absolutas, o conhecimento pronto e acabado. Ao contrário desta concepção, o conhecimento, assim como a ciência, são construídos socialmente estando em constante movimento. Assim, acreditamos que cabe ao educador adotar uma postura de pesquisador, crítico e reflexivo, com o intuito de aprimorar sua prática pedagógica transmitindo não apenas conteúdos, como se os alunos fossem uma tábua rasa a ser preenchida, mas principalmente, alguém que nutre o aluno de elementos capazes de decodificar o mundo e os conflitos inerentes a sua realidade.

Adotando estes posicionamentos, acreditamos que a articulação Educação Ambiental e Ensino de Ciências no contexto da alfabetização possibilite a legitimação do indivíduo enquanto leitor crítico do mundo, ajudando-o a compreender, não apenas, os fenômenos e processos científicos, 
mas os conflitos socioambientais estabelecidos na realidade. No sentido desta contextualização Chassot coloca que:

Ensino de ciências para a formação da cidadania, evidenciando que ele precisa ser socialmente contextualizado, destacando o papel social da Ciência e suas interações multidisciplinares com os aspectos sociais, políticos, históricos, econômicos e éticos, diferentemente do modismo do ensino do cotidiano que reproduz uma concepção de ciência pura e neutra (CHASSOT, 2004, p.47)

\section{EDUCAÇÃO AMBIENTAL E A ALFABETIZAÇÃO}

Para Emília Ferreiro, o processo de alfabetização de uma criança tem início muito antes dela entrar na escola. Desde muito cedo a criança é capaz de colocar problemas, criar hipóteses, testá-las e construir interpretações para tentar entender o mundo que a cerca. Telma Weisz (2005) faz uma referência ao método de alfabetização desenvolvido na década de 70, onde o aluno para aprender a ler e escrever deveria desenvolver um conjunto de habilidades perceptivo-motoras, tal como enfatiza:

Ou seja, as crianças precisavam alcançar uma maturidade, uma 'prontidão' sem a qual nem valia a pena ensiná-las. Dessa maneira, as escolas aplicavam às crianças um conjunto de exercícios que serviam também para avaliar o desempenho em relações a essas habilidades (WEISZ, 2005, p.8).

Emília Ferreiro revoluciona conceitualmente a alfabetização através da psicogênese da língua escrita, onde o foco da investigação sobre as questões de alfabetização mudou radicalmente para "como se ensina" e "como se aprende". Dessa forma, o sujeito se tornou ativo e inteligente, sendo capaz de pensar, elaborar hipóteses e compreender o mundo em que vive.

Segundo Paulo Freire (1982) a criança, muito antes de ler o texto escrito é capaz de interpretar o mundo em que vive - isso se consubstancia em uma 
boa pista para pensarmos em práticas alfabetizadoras que tirem a criança da ausência e explorem o diálogo entre o educador e educando, afinal, o conhecimento infantil nunca é neutro e deve ser considerado e contextualizado.

A alfabetização pressupõe uma pedagogia da escuta, da voz e do ouvido, por isso Paulo Freire (1982) acreditava que, a verdadeira prática alfabetizadora deve legitimar os saberes das crianças, ouvindo-as. Desta forma, o Ensino de Ciências e a Educação Ambiental na alfabetização permitem a aquisição da linguagem e articulação do pensamento auxiliando na compreensão das relações com e no mundo.

Além disso, podemos lembrar também do princípio da alteridade, ou seja, devemos enxergar a criança como um ser crítico e ativo na dinâmica do espaço escolar e do processo de ensino/aprendizagem. Para a criança aprender a ler e escrever deve pensar no que está sendo escrito e não só decodificar o código da língua escrita, mas fazer relações e mediar valores ao sentido as palavras. Um dos debates referentes ao campo recai justamente no lugar que assume o erro neste processo, conforme expõe Esteban:

(...) ele é motivo de preocupação. Não ocorrem, entretanto, perguntas sobre o próprio padrão usado, seus fundamentos e sua relação com as crianças concretas que ele estão submetidas. Não se questiona por que e como constrói o erro (ESTEBAN, p. 28,1997).

O erro entendido como parte do processo ensino/aprendizagem pode ser avaliado como construtivo por possibilitar a criança elaborar seu próprio conhecimento, ultrapassando etapas. O professor, no entanto, comumente reprime a construção do conhecimento dos alunos reafirmando o peso do erro e gerando um sentimento de culpa. Desta forma, se faz necessário rever o lugar do erro nas práticas docentes, começando por assumir o erro nas próprias práticas e como algo comum ao desenvolvimento humano, assim como, do desenvolvimento cognitivo infantil, tal como nos elucida Aquino: 
A idéia de ciências na educação tem sido associada aos conteúdos das disciplinas escolares e, nesse sentido, é totalmente inadequado para a Educação Infantil. $O$ que estamos propondo é discutir a necessidade de um olhar diferente para as ações e indagações das crianças sobre o mundo natural e tecnológico, particularmente por parte das professoras de Educação Infantil. Consideramos especialmente relevante discutir o lugar do "erro" no processo do desenvolvimento cognitivo, procurando identificar as contribuições teóricas sobre o pensamento infantil. De outra parte, precisamos compreender o "erro" das professoras em sua prática docente (AQUINO, 2002, p. 56).

Acreditamos que para as crianças que estão no início da aquisição da linguagem e da elaboração do pensamento, o contato com a Educação Ambiental como leitura e apropriação do mundo possa contribuir para estimular a nomeação, classificação e apropriação crítica do mundo que a cerca. Neste contexto, o Ensino de Ciências nas práticas alfabetizadoras se coloca como um ambiente propício para inserção das temáticas socioambientais postas desde a mais tenra idade. A necessidade desta abordagem considera a dinâmica da sociedade contemporânea em que, cada vez mais, os aspectos tecnocientíficos se inserem na cotidianidade, sendo a criança um sujeito integrante do corpo social, conforme discorre Correia:

podemos compreender que as que crianças não são adultos em miniatura e sim sujeitos que possuem uma maneira particular de significar o mundo que os cerca. Não são o "futuro" e sim o "hoje", sujeitos integrantes de um corpo social e que, portanto, têm o mesmo direito que os adultos de apropriar-se da cultura elaborada pelo conjunto da sociedade para utilizá-la na explicação e na transformação do mundo (CORREIA apud FUMAGALLI, 1998, p. 15).

A Educação Ambiental proposta pelos Parâmetros Curriculares Nacionais (PCN) como tema transversal, se apresenta como uma necessidade atual buscando estabelecer a relação sociedade/natureza, tanto na dimensão coletiva quanto individual. O Ensino de Ciências Naturais nos PCN deve ter, conforme enfatiza Sanchez, a premissa de levar os alunos a: 
Compreender a natureza como um todo dinâmico, sendo o ser humano parte integrante e agente de transformações do mundo em que vive; Identificar relações entre conhecimento científico, produção de tecnologia e condições de vida, no mundo de hoje e em sua evolução histórica; Formular questões, diagnosticar e propor soluções para problemas reais a partir de elementos das Ciências Naturais, colocando em prática conceitos, procedimentos e atitudes desenvolvidos no aprendizado escolar; Saber utilizar conceitos básicos, associados à energia, matéria, transformação, espaço, tempo, sistema, equilíbrio e vida; Saber combinar leituras, observações, experimentações, registros, etc., para coleta, organização, comunicação e discussão de fatos e informações; valorizar o trabalho em grupo, sendo capaz de ação critica e cooperativa para a construção coletiva do conhecimento; compreender a saúde como bem individual e comum que deve ser promovido pela ação coletiva; compreender a tecnologia como meio para suprir necessidades humanas, distinguindo usos corretos e necessários daqueles prejudiciais ao equilíbrio da natureza a ao ser humano (SANCHEZ, 2007, p.31)

\section{O ENSINO DE CIÊNCIAS E A ABORDAGEM CTSA}

Segundo Gouvêa e Leal (2001, p.68), a ciência e tecnologia adquirem considerável status a partir da $2^{\text {a }}$ Guerra Mundial do século XX, por demonstrar, sua capacidade de aprofundar conhecimentos, trazer soluções e proporcionar comodidades de toda ordem. No entanto, diante do poderio destrutivo das bombas nucleares e das conseqüências ambientais do modelo de produção e consumo legitimado pela ciência e tecnologia, a sociedade começa a questionar a neutralidade da ciência e suas implicações na sociedade e ambiente. No bojo deste processo surgem movimentos ambientalistas, movimentos contra-cultura e o movimento Ciência, Tecnologia e Sociedade (CTS), que mais tarde incorpora e reforça a dimensão política do "Ambiente", atualmente denominado por algumas autores como CTSA. 
O movimento CTS surge na Europa e nos países anglo-saxões, tendo em vista, a necessidade de ampliar os estudos epistemológicos da ciência, momento em que se questiona a unilateralidade tecnocrática e se reivindica participação ou algum controle da sociedade no desenvolvimento das atividades científico-tecnológica, uma vez que denotam desdobramentos de diversas ordens, tal como, no âmbito social, político, econômico e ambiental.

Segundo Reigota (2007) no Brasil, tanto a educação ambiental, quanto o pensamento CSTA são herdeiros do pensamento pedagógico crítico e propositivo de Anísio Teixeira, Paulo Freire e Darcy Ribeiro, entre outros.

O domínio, cada vez maior, do conhecimento científico e tecnológico coloca em questão a necessidade de uma sociedade cientificamente alfabetizada, ou dizendo de outra forma, "uma população com capacidades e compreensão suficientes para entender e seguir debates científicos e envolverse nas questões que a tecnologia coloca, quer para eles como indivíduos que para a sociedade como um todo" (Tenreiro-Vieira e Vieira, 2005, p.194).

Para Gouvêa e Leal (2001, p.70), os desafios educacionais da atualidade devem preparar, em tempo cada vez menor, indivíduos para viver em contextos plurais, articulando teoria e prática. As autoras entendem alfabetização científica e tecnológica como aquilo que o público deve saber sobre CTS com base em conhecimentos adquiridos em contextos diversos, entendido ainda, como atitude pública e acesso a informações obtidas em meios de divulgação científica e tecnologia.

De acordo com Solomon o contexto da globalização reforça a necessidade da alfabetização científica e tecnológica ser sustentada em "sólidas bases morais e sociais", devendo:

visar, sobretudo, ao desenvolvimento de atitudes para enfocar e solucionar, de modo significativo, os problemas de aplicação da ciência na sociedade, além de ensinar a compreender 0 modo como a ciência atua no contexto social (apud GOUVÊA e LEAL, 2001, p.71). 
Nesta conjuntura, Auler e Bazzo (2001) colocam algumas questões relativas ao contexto brasileiro, como por exemplo, o fato do movimento CTS ter surgido em países que tiveram seu crescimento pautado no modelo de desenvolvimento à que pretendemos alcançar e que seria imanente ao imaginário de muitos brasileiros aspirar a lógica capitalista de produção e consumo destes países. Assim, os autores questionam em que medida os professores de ciência estariam reproduzindo esta racionalidade, qual concepção ciência e tecnologia permearia suas práticas de ensinoaprendizagem? Quais relações CTSA seriam colocadas a prova nas opções de cotidianidade? Esta preocupação pode ser elucidada no seguinte trecho (ibid., p.3):

Considerando o discurso dos meios de comunicação e de outros segmentos formadores de opinião, não seria meta prioritária de parcela significativa da população a busca do "primeiro mundo"? Não estaríamos querendo fazer uso das mesmas estratégias em termos de política econômica e tecnológica, esquecendo/ignorando suas conseqüências em termos ambientais, culturais e sociais?

\section{CONSIDERAÇÕES FINAIS}

Tendo em vista a concepção discursiva proposta por Smolka (2008) onde "a alfabetização é um processo discursivo: a criança aprende a ouvir, a entender o outro pela leitura; aprender a falar, a dizer o que quer pela escrita", acreditamos que os desafios postos por este projeto de pesquisa seja evidenciar e problematizar as práticas alfabetizadoras, considerando que:

O que acorre na atualidade é uma prática educativa funcional à lógica científica instrumental e positivista que fragmenta a realidade e à eficiência produtiva inerente ao capitalismo, 
mercantilizando-nos e a todos os seres vivos (LOUREIRO, 2004, p.78)

Ainda que, estejam postas as dificuldades em ultrapassar a prática conteudista, fragmentada e descontextualizada no ensino de ciências, seu contrário se coloca como uma possibilidade para formação crítica que condicione o educando a dar significado aos conteúdos científicos na compreensão da complexidade do mundo e leitura crítica das relações que se estabelecem entre Ciência, Tecnologia, Sociedade e Ambiente. Desta forma:

\begin{abstract}
A formação científica das crianças e dos jovens deve contribuir para a formação de futuros cidadãos que sejam responsáveis pelos seus atos tanto individuais como coletivos, conscientes e conhecedores dos riscos, mas ativos e solidários para conquistar o bem-estar da sociedade e críticos e exigentes diante daqueles que tomam as decisões (WEISSMANN, 1993 apud MALAFAIA Y RODRIGUES, 2008).
\end{abstract}

A articulação do projeto "Que bicho é esse?" no Fórum de Alfabetização, Leitura e Escrita (FALE) possibilitou o diagnostico de um campo de conflitos simbólicos presentes nas narrativas das professoras alfabetizadoras. Conforme exposto por Auler e Bazzo (2001), a presença de anseios pelo modo de produção e consumo dos países desenvolvidos nos leva a questionar, em que medida, esta racionalidade está presente no cotidiano das professoras alfabetizadoras e como se reproduz no âmbito do ensino de ciências. Esta consideração se coloca basilar, no sentido de que, os desdobramentos de suas práticas de ensino-aprendizagem dependem, em grande parte, da maneira como percebem as interações entre (C) Ciência, (T) Tecnologia, (S) Sociedade e (A) Ambiente. Assim, optamos pela abordagem teórica CTSA considerando que esta nos possibilite compreender o ensino de ciências e a educação ambiental nas práticas alfabetizadoras, tendo em vista, um campo de conflitos simbólicos e a complexidade do tema que abrange interfaces sociais, científicas, tecnológicas e ambientais. 


\section{REFERÊNCIAS}

AQUINO, Lígia Maria Leão. O lugar do erro na Educação Infantil: a construção do conhecimento das professoras. Tese de Niterói, UFF, 2002. Disponível

em: $<$ http://www.bdtd.ndc.uff.br/tde busca/pastaTrabalhos.php?listaDetalhes\%5B\%

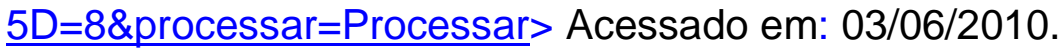

AULER, D.; BAZZO, W. Reflexões para a implementação do movimento CTS no contexto educacional brasileiro. Revista Ciência e Educação, v7, n1, p. 113, 2001.

BRASIL. Secretaria de Educação Fundamental. Parâmetros curriculares nacionais : Ciências Naturais / Secretaria de Educação Fundamental. . Brasília : MEC / SEF, 1998. Disponível em: $<$ http://portal.mec.gov.br/seb/arquivos/pdf/meioambiente.pdf> Acessado em: 03/06/2010.

BRASIL, Ministério da Educação e do Desporto. Secretaria de Educação Fundamental. Parâmetros Curriculares Nacionais: Temas Transversais, Meio Ambiente. Ministério da Educação e do Desporto. Secretaria de Educação Fundamental. Brasília: MEC/SEF. Disponível em: $<$ http://portal.mec.gov.br/seb/arquivos/pdf/meioambiente.pdf> Acessado em: 03/06/20010.

CERTEAU, Michael. A invenção do cotidiano: 1. Artes de fazer. Petrópolis, RJ: Vozes, 1994.

CHASSOT, A. Alfabetização Científica: questões e desafios para a educação. 4 ed. ljuí: Unijuí, 2006

CORREIA, E. Por que ensinar Ciências na escola fundamental? Disponível em: $\quad<$ http://www.meuartigo.brasilescola.com/educacao/por-que-ensinarciencias-na-escola-fundamental.htm.> Acessado em 16/10/2009ESTEBAN, Maria Teresa. Jogos de Encaixe: Educar ou formar desde a pré-escola?. In: Revisitando a pré-escola. 3 ed, São Paulo: Cortez, 1997.

FREIRE, Paulo. A importância do ato de ler. São Paulo, 1982.

FREIRE, Paulo. Pedagogia da Autonomia: saberes necessários à prática educativa. 34 ed. São Paulo: Paz e Terra, 2006. 


\section{FÓRUM AMBIENTAL DA ALTA PAULISTA}

Volume VI - Ano 2010

FREIRE, Paulo. Pedagogia do Oprimido, 4⿳亠丷⿵冂⿱⺊口灬 edição,Rio de Janeiro, Paz e Terra, 1977.

GADOTTI, Moacir. A pedagogia da terra e a cultura da sustentabilidade. Disponível

em: $\leq$ www.fadepe.com.br/.../4 fina controjoselice pedagogiadaterrraesustenta bilidade.doc. > Acessado em: 03/06/2010.

GOUVÊA, G.; LEAL, M.C. Uma visão do ensino de ciência, tecnologia e sociedade na escola e em um museu de ciência. Revista Ciência e Educação, v.7, n.1, p. 95-11, 2001.

LOUREIRO, C.F.B. Educação Ambiental Transformadora In: BRASIL. Ministério da Educação. Diretoria de Educação Ambiental. Identidades da educação ambiental brasileira. Brasília, 2004.

MALAFAIA,G; RODRIGUES,A. S. L. Uma reflexão sobre o Ensino de Ciências no Nível Fundamental da Educação, Ciência e Ensino, v. 2, n.2, junho de 2008.

REIGOTA, M. O estado da arte na pesquisa e na educação ambiental no Brasil. Pesquisa em educação ambiental, v.2, n1, p.33-66. 2007

TENREIRO-VIEIRA, C.; VIEIRA, R.M. Construção de práticas didáticopedagógicas com orientação CTS: impacto de um programa de formação continuada de professores de ciências do ensino básico. Revista Ciência e Educação, v11, n2, p. 191-211, 2005.

WEISZ, Telma. Emília Ferreiro: A construção do conhecimento. Revista Viver Mente \& Cérebro. Coleção Memória da Pedagogia, n. 5. Rio de Janeiro: Ediouro; São Paulo: Segmento-Duetto, 2005.

SANCHEZ, Celso. O que é ensino de ciências? A aula de ciências características e contextualizações. 2007.

SMOLKA, Ana Luzia Bustamante. A criança na fase inicial da escrita: a alfabetização como processo discursivo. 2008. 12a edição. Ed. Cortez. São Paulo. 